\title{
Development of a burner to measure biogas generation
}

\author{
E. Godoy Junior ${ }^{1,3,4}$, J. R. Camargo ${ }^{1,3}$, M. A. Marcelino ${ }^{1,2}$ \\ \& J. L. Silveira ${ }^{2,3}$ \\ ${ }^{I}$ Department of Mechanical Engineering of University of Taubaté, \\ UNITAU, Brazil \\ ${ }^{2}$ Department of Energy, State University of São Paulo, Brazil \\ ${ }^{3}$ Productivity and Technology Development in Innovative Extension, \\ National Council for Scientific and Technological Development, \\ CNPq, Brazil \\ ${ }^{4}$ Poly Easy do Brasil, Brazil
}

\begin{abstract}
This paper describes the development of a system of an automated biogas burner which records the amount of biogas burnt by a biogas low flow system. The biogas produced in mini SST biodigestors, (mini station of sewage treatment), in a rural and residential area where there is a low production of biogas does not economically justify its energy; it is only functioning as an anaerobic waste treatment. The registration system of burnt biogas correctly calibrated may be homologated to obtain carbon credits. In these systems of anaerobic waste treatment, due to the low flow of biogas discharged into the atmosphere and the inclusion of methane, it has a destructive potential 21 times greater than $\mathrm{CO}_{2}$. The system developed was analysed and the effects of the disposed gas produced by burner and converting it into $\mathrm{CO}_{2}$ proved to show less environmental impact. The automated system used in the small sewage treatment plants was almost insignificant when analysed separately, but when taking several systems working together into consideration there was a considerable positive environmental impact.

Keywords: biogas, biogas emission, environmental sanitation, automated burner, anaerobic waste treatment.
\end{abstract}




\section{Introduction}

This work is aimed at developing a system of an automatic biogas burner that also records the volume of biogas burned in a low flow system, where the biogas produced in mini ETEs (mini stations of sewage treatment of rural and residential small biodigestors, where, due to the low production of biogas, does not economically justify its energy. The emphasis is on health and of the anaerobic treatment of waste.

The main advantage to burning methane in biogas is because it is a greenhouse gas that has 21 times more impact to the atmosphere than $\mathrm{CO}_{2}$. There is not much literature available because it is technology protected by patents. An extensive literature search returned just a few published articles on the Biogas burners automatically registered for clean development mechanisms.

The relationship of untreated sewage disposed of in fresh water bodies, causing eutrophication of waters, the uncontrolled production of biogas which aggravates the greenhouse effect, the spread of disease hydrotransmitted and the incidence of strong rains with their consequences are illustrated in Figure 1.

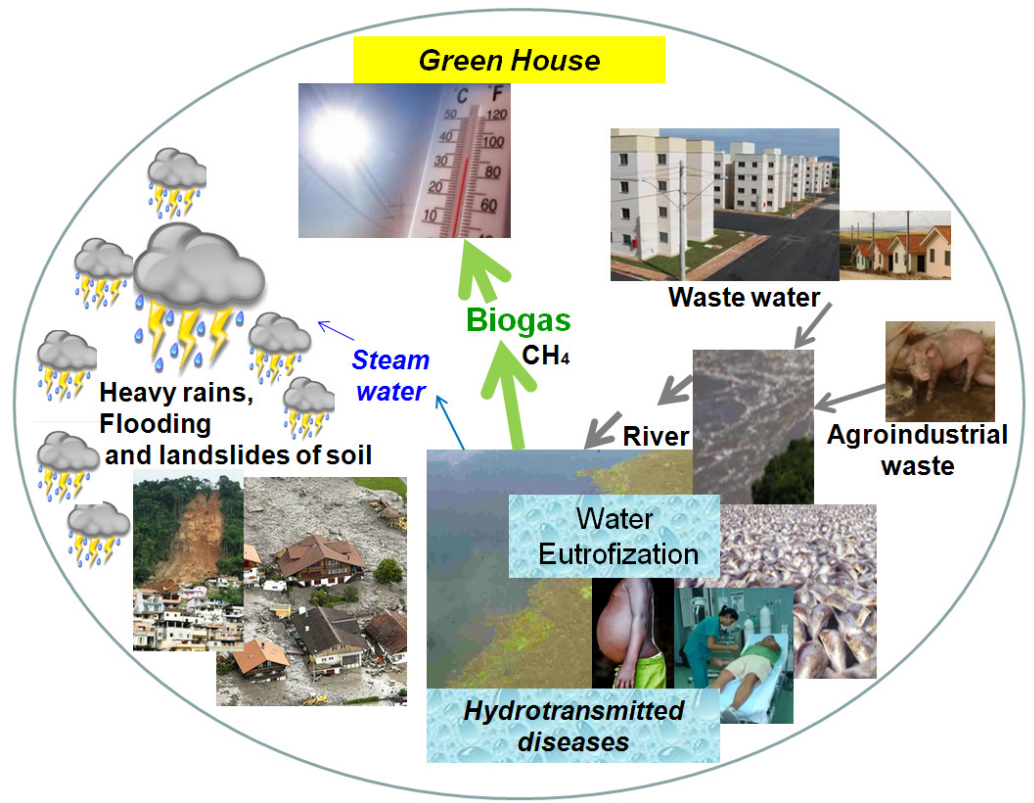

Figure 1: Relationship between the untreated sewage, the uncontrolled production of biogas and high incidences of heavy rainfall and its consequences.

Some consultations with international suppliers of traditional automatic burner recorders for clean biogas development mechanisms, showed that this type of technology is not yet available for small flows of biogas produced, either 
by neglect, high cost, or lack of technological mastery in this area. However, these few discarded flows in the atmosphere; when computed together, promote a considerable impact not to be discounted and are subject to mitigation measures. It is worth noting that in sewage treatment plants and anaerobic digesters that promote rural energy use of biogas, there is still a need of the unit for gas burning that cannot be stored. It is also important that the system is capable of being applied to oil and gas platforms.

\subsection{The state of the art biogas burners systems for environmental sanitation}

According to Turns [1], for a mixture of biogas-oxygen to reach the flash point it is required to have a minimum temperature sufficient to enrich the mixture. There are three practical ways to achieve this heat source: a pilot flame, a spark or an incandescent filament.

The pilot flame is not recommended for intermittent production of biogas because of energy costs to keep it lit.

The same also for an incandescent filament in a lamp in particular gas, because of its short life span. In the atmosphere the filament is off, thus reducing even more the life span.

There are several types of lighters whose source of heat is the spark, incorporated into the gas ovens; the most common model provides the spark by the impact of a rod against a piezoelectric crystal that generates a small electric current, capable of creating a spark sufficient to trigger the combustion of fuel gas.

Other types of lighters use a transformer that increases the voltage of the home power network values quite high, this voltage is applied to two electrodes arranged properly, causing the ionization of air between them. The isolation imposed by air $(3 \mathrm{kV} / \mathrm{mm})$ disappears momentarily between the electrodes, and consequently produces an electrical discharge that glows in the gas-air mixture.

In general the lighters are known as igniters. The conventional model of continuous igniters causes the desired electromechanical phenomenon when driven by a pair of contacts which feed the processor. Switching on and off by a mechanical key or switch and controlled by a coil which in turn produces a high amplitude transient electric, inducing high voltage in the secondary. But, like any operating system has low reliability. These devices have a short shelf life, and generate high noise and electromagnetic noise in the environment. In general these igniters generate around $240 \mathrm{sparks} / \mathrm{sec}$.

Currently there are igniters which produce a spark by solid state. These use electronic igniters in semiconductor switching. This generates a large increase in the lifetime of the device and also substantially reduces the noise and electromagnetic noise generated. In general these igniters generate around 30 to $60 \mathrm{sparks} / \mathrm{sec}$.

The electronic circuits have significant reduction in consumption of electricity and are isolated from resin, reducing the risk of explosion due to leakage of unwanted gas.

The first circuits used the spark and the gas, but were better than the devices of maneuver even though the failure rate is still high. Other circuits, which use a 
SIDAC for switching (silicon diode is AC), is a component with the equivalent curve as a NEON lamp, however, is solid-state and bidirectional. The spark and gas has a cost greater than a SIDAC according to Shindengen [2] and Littelfuse [3].

Generally these circuits are fed with AC voltage from the network, between 90 to 240 Vrms. The circuit, through a folder of tension, with a capacitor which stores a charge for a few cycles from the network. When the voltage reaches the firing of SIDAC, the primary transformer is fed with about $270 \mathrm{~V}$, inducing in the secondary approximately $20 \mathrm{kV}$ which determines the voltage in the secondary and the distance between the electrodes. Each electrode is $4 \mathrm{~mm}$ distant from the earth second (Nóbrega [4]).

The igniters' communications are produced successively feeding 4 to 6 mouths of a stove, and the furnace. This totals 5 to 7 simultaneous sparks. A very common problem in stove igniters is due to the accumulation of fat on the electrodes, the spark is often greater than the isolation of any alternative path, even within the igniter. With continuous use in this condition the internal igniter gets damaged.

To avoid the rupture of internal insulation, a way to spark alternatively is offered by means of a construction supervisor with a piece of copper conductor. The supervisor sparks between the electrodes at a distance of two times the nominal distance between them, but located in the igniter housing $(8 \mathrm{~mm})$, therefore; when there is an impediment to spark break the air at the end of the electrodes, it finds an alternate path outside the igniter, thus protecting the internal components of the same.

This further increases the life of the igniter, which in normal operation, is specified to withstand at least 100,000 operations, with cycles of 3 seconds on and off for 12 seconds as Invensysappliance [5].

\section{Material and methods}

\subsection{Local development of the study}

This work is being developed in the laboratories of the University of Taubate and UNESP Campus de Guratinguetá.

\subsection{Setting up the generator flashpoint burner system for sewage treatment ministrations}

To use the igniter in a biogas burner for about $80 \%$ methane and $20 \%$ carbon dioxide produced in sewage treatment ministations, the three main aspects to be examined are: 1) time of life - because even after having generating a spark and the process of burning gas has begun, the igniter will continue to generate the spark, because if the flame goes out for any reason it would automatically be lit; 2) generation of spark - the igniter will generate just one spark at a time instead of 5 or 7 as in cooking. This will allow the energy stored in the capacitor to be delivered to only one electrode. As the dimensions need not be reduced for this 
application, a special reel for the processor could be developed; 3) installation of the electrodes - The igniter can be fitted with the electrodes, being installed near the point of exit of the gas, this allows for length reduction of the conductors. On the stove the igniters are required to stay away from the heat generated in the mouths and the furnace.

Figure 2 illustrates the circuit of the igniter for the company "Brascabos Components Electrical and Electronic Ltda" Already adapted to a single nozzle second Marcelino [6].

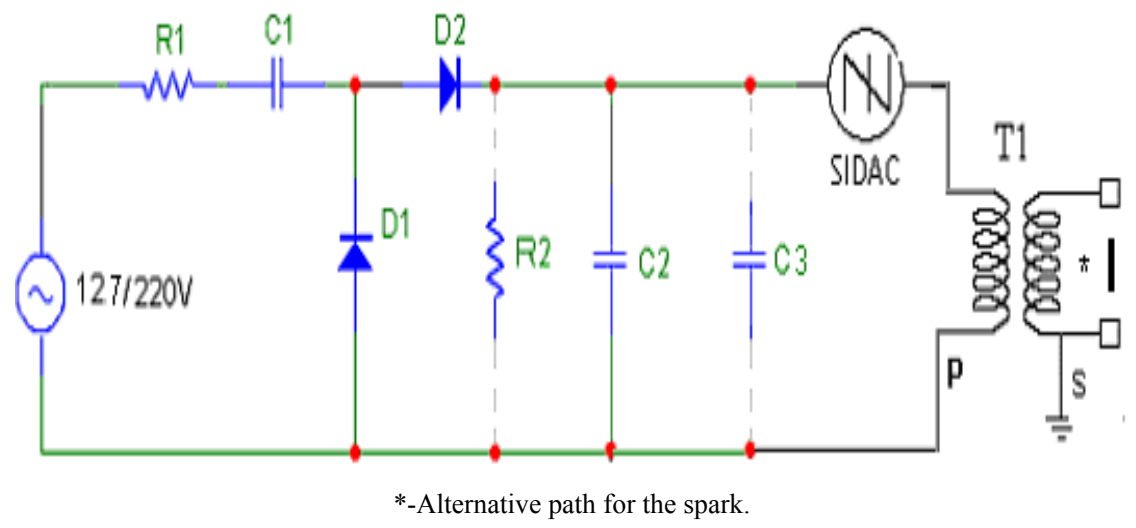

Figure 2: $\quad$ Example of sound diffusion from a wall.

The gas tank, shown in Figure 4, is equipped with two microswitches: which mark the end of the course, installed on top of the gas meter, which indicates that it is full (GC), and another that marks the beginning of course, installed at the bottom, which indicates that it is low on gas $(\mathrm{GV})$.

A valve with an electric drive is installed at the exit of the gas tank. It will always be linked with the igniter when the key is activated GC.

Today, through a slip slop operation, a timer is armed (E) which activates the igniter with a period of 5 seconds, 1 - on.2.3.4 - off.

This operation will continue even if the key GC is off, indicating it is not completely filled until the key is turned GV, indicating that it is empty or almost. Currently beyond the igniter, the valve will be turned off (closed). Even if the key GV off (indicating that the gas tank is no longer empty), the system will only be activated again, if the key is activated GC.

That this hysteresis, i.e. the tendency of a material or system to keep their properties in the absence of a stimulus that has generated, is performed successfully, it is necessary that there is a hardware filter to remove the mechanical key and subcultures electromagnetic noise. This filter is covered by the transaction type slip slop SR.

The process described by GC keys and GV summarizes a transaction of a type multivibrator slip slop SR (Set/Reset), Table 1 describes this function. 
Table 1: Description of the functions of the burner system switch.

\begin{tabular}{|c|c|c|c|}
\hline \multicolumn{2}{|c|}{ Inputs } & \multicolumn{2}{c|}{ Outputs } \\
\hline Set $(\mathrm{GV})$ & Reset $(\mathrm{GV})$ & Valve & Igniter \\
\hline On & off & on & 1 on/4off \\
\hline Off & on & off & off \\
\hline Off & off & (previous state) & (previous state) \\
\hline On & on & (State prohibited) & (State prohibited) \\
\hline
\end{tabular}

The condition of state will not automatically be guaranteed in the gas tank, as illustrated by Figure 4, and when the two keys are off it is the condition where the gas tank is with gas volume and in the process of burning. Figure 3 illustrates the block diagram of the control system of the burner and recorder.

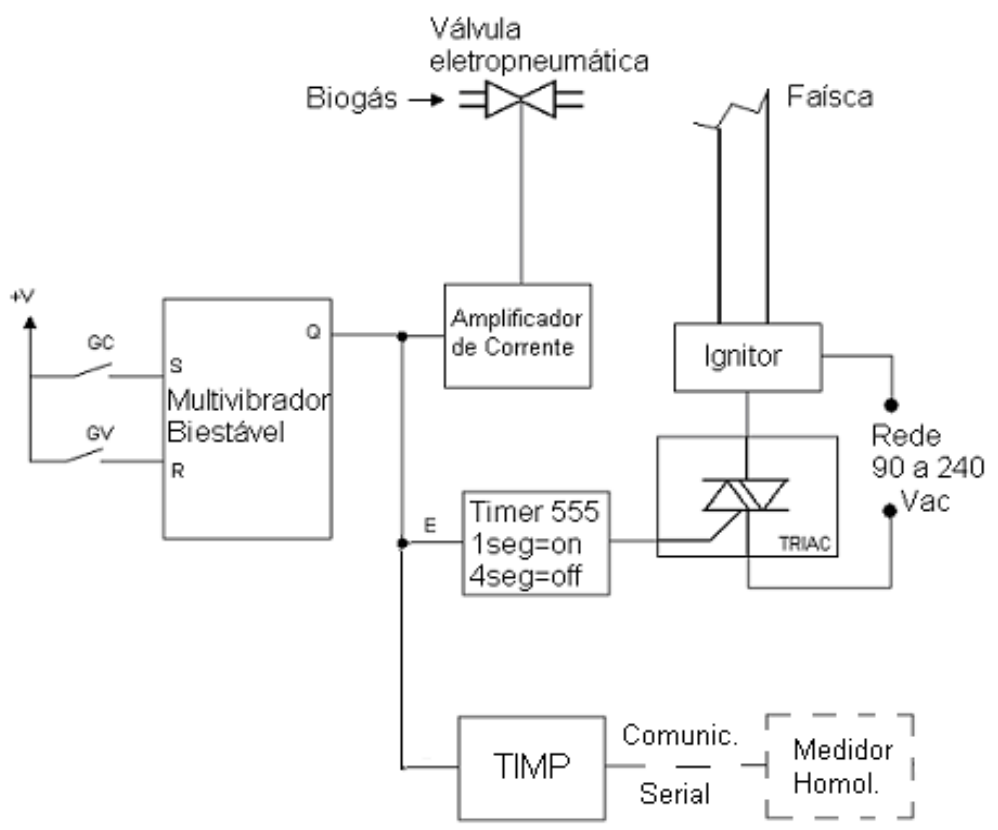

Figure 3: Control system of the burner and recorder.

Mechanical solutions have been conceived so that the flame is only extinguished when the valve will be closed. Any accidental deletion will be supplied by the following spark, in less than 4 seconds.

\subsection{Burnt biogas recording system}

To register the volume of biogas burnt and get the carbon credits, it is intended to adapt the TIMP (intelligent timer with signaling for preventive maintenance) 
according to Marcelino [7]. The system counts the number of times that the gas tank is filled and, emptied, with the respective burning.

The system guarantees burnt minimum volume registering, whilst during the burning, biogas can enter, and considering that the total will be made by the number of times that key GC is closed, during the time where the signal Q leaves " 0 " and goes for " 1 ".

In the future, for systems with a higher production of biogas, to achieve more precision in the biogas volume burnt an auxiliary gas tank could be installed before the main gas tank, and, with an electro pneumatic valve installed between the two. This valve will only be closed when the burning process is activated.

For systems with a small volume of biogas, were it is not necessary to guarantee the volume burnt exactly, but enough only to guarantee the burnt minimum volume. This you justify since the burning process is very fast compared with the filling time of the gas tank.

-The intelligent timer that enters the number of transitions " 0 " for " 1 " in exit "Q" of the type slip slop multivibrator remains, for serial communication, requesting authorization for the sending of the entered total. If there is no reply authorizing it continues counting. In case there is equipment, duly homologated for the depositing system of carbon credits, either connected to the serial communication, or authorizes the transmission of the total number of times that the gas tank was unloaded, and the communication was successful, the totalizer is zeroed. Figure 4 illustrates the electro mechanic burn biogas volume recording system.

Figure 6 illustrates the model and the prototype of the burnt biogas system. Figures 4 and 5, according to Godoy et al. (2009), illustrates the operation of the electromechanical system register the volume of biogas burned, representing the system in the empty state, without biogas, in which: (1) is the inlet of the biogas, (2) is the bottom of the gas tank, (3) is the lead ballast to keep the bell of the gasometer upright, (4) is a hole in the bottom of the gasometer (5), so that in the absence of electricity, biogas is released without firing if the volume exceeds the capacity of the gas tank, (6) is a permanent magnet that activates the DIP (7) in the empty position of biogas and (8) in the position full of biogas; (9) is an elongated flexible tube in position, which carries the biogas to the exit (10) that connects to the valve (12) that controls the output of biogas for burning; (11) is the spark, (13) are holes for the air inlet in the fuel mixture; (14) is the protector of the flame; (16) is the burner tip and (15) is the electrode of the spark.

Figure 4, according to Godoy et al. (2009), illustrates the full, complete and operation of biogas-burning, and the register of biogas burned, where: (5) represents the gas tank full of biogas, (6) represents the permanent magnet in the upper position engaging the micro switch (8), which provide a signal to record the volume of biogas and trigger the opening of the valve (12), and the firing of the spark (11), (9) represents the flexible tube stowed, leading to biogas output (10) that connects the valve (12), which controls the output from biogas combustion, which is in the open position; (11) represents the spark gap functioning, (17) is the flame burning biogas; (18) are the bubbles of biogas which will fill the gas tank (5). 
Figure 4, compared to Figure 5, clearly illustrates the operation of the recorder burner biogas, since the position empty until the position filled, with the onset of burning and the measurement of biogas burned without energy recovery to the target, only aiming at the environmental sanitation of biogas.
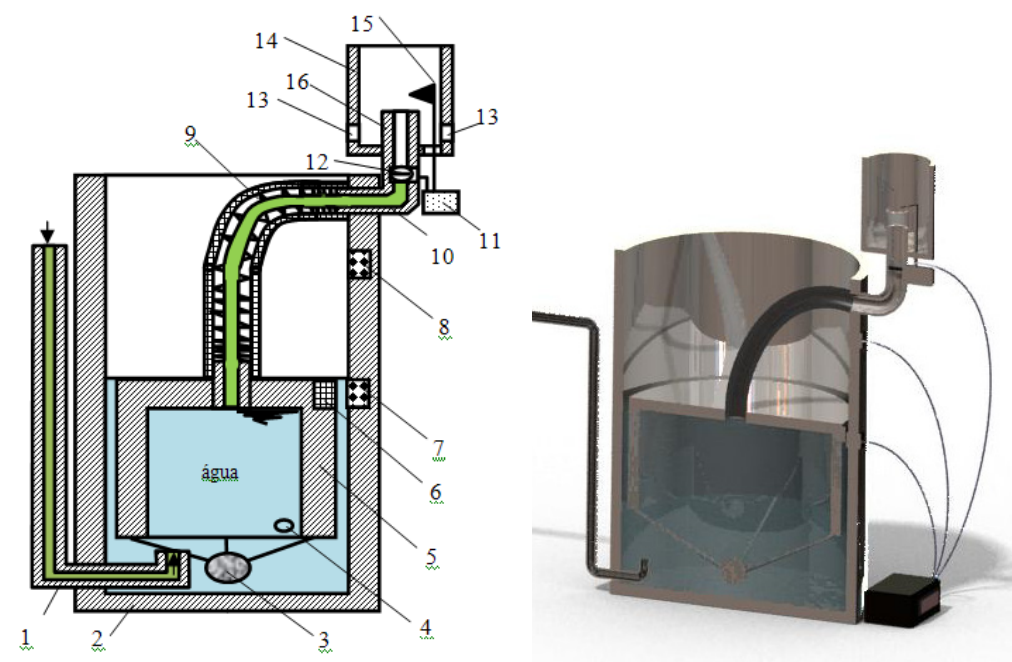

Figure 4: Illustration of the biogas burner system register empty.
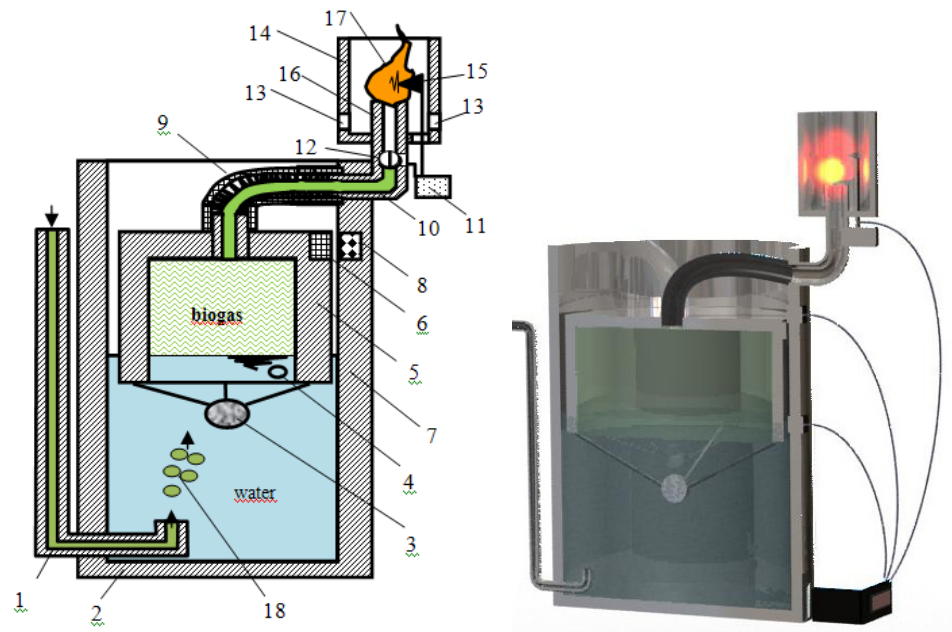

Figure 5: Illustration of the biogas burner system register in position complete and combustion of biogas. 

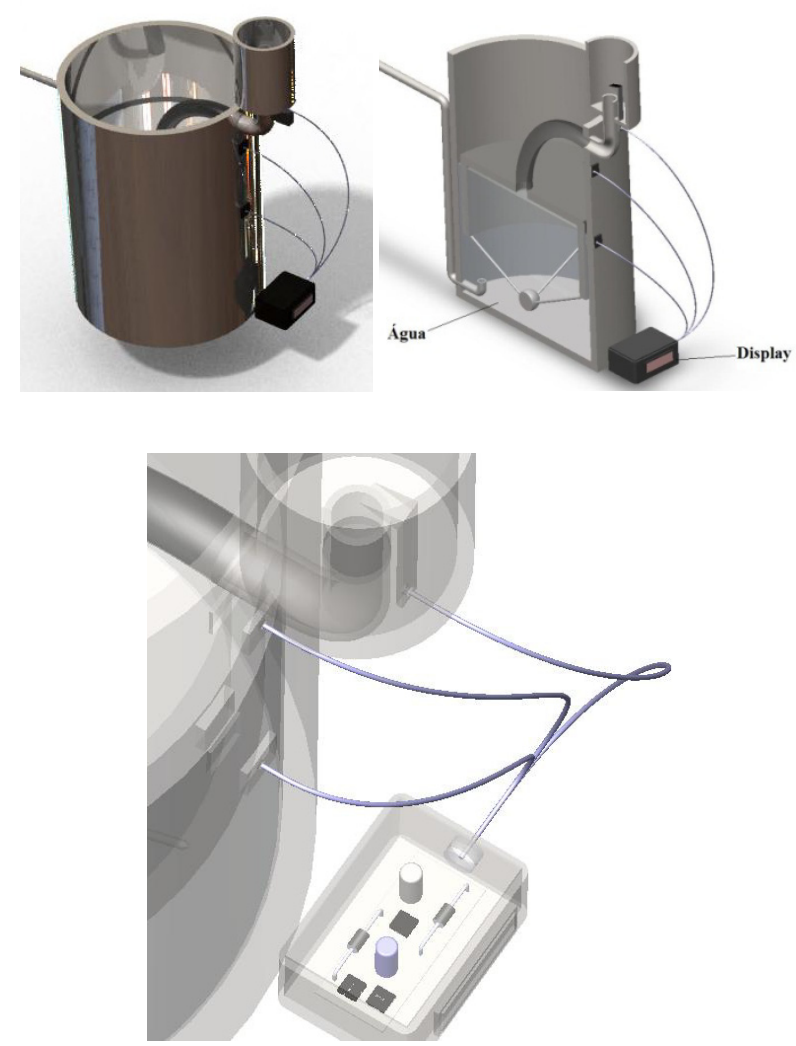

Figure 6: Drawings of the model focusing on the burner control system and record.

\subsection{TIMP description}

The system intelligent timer with signaling for preventive maintenance is mounted in a printed circuit, with reduced dimensions and low cost.

The system is constructed with a commercial microcontroller of 8 bolts, equipped with not-volatile memory of programming and electric deletion, EEPROM (Electrical Erasable Programmable Read Only Memory), as well as an internal clock for marking the time. Depending on the necessity for precise time for preventive maintenance, the time base can be outside the microcontroller.

The power source which comes from the national network 127 or 220 volts $\mathrm{AC}$ is converted by tension rectifier, capacitor and tension regulator.

The operation is signaled by a LED which in normal operational situations is always a light, representing that the volume of biogas being burnt is being counted.

The system is equipped with a push button switch which serves for manual biogas counting operations; also it ensures that the external equipment that does the counting can receive regular communications ensuring total success. 


\section{Results}

The expectation is that this system will enable the quantification and the burning of the biogas burnt in small quantities where it is impracticable for its low energy value.

The benefits of the proposed system would not be noticeable in an isolated system, whereas the target is smaller installations that do not represent large volumes of greenhouse gases given off. In a superficial analysis, one realizes that although the small size of treatment plants, when the recorded amount of biogas produced and its environmental impact, or due to their own awareness of the population, they can represent a significant number in the near future. And together, they can generate significant protection to reduce the greenhouse effect, if equipped with automatic burner versions of this study.

The system QRBBV associated with an anaerobic digester to treat sewage and wastewater from small farmers $\mathrm{CH}_{4}$ converts to $\mathrm{CO}_{2}$. This reduces by at least 21 times the impact caused by $\mathrm{CH}_{4}$ in biogas, with the reduction of greenhouse gas, may include working with the mitigation of disasters due to the high incidence of rains that cause flooding, landslides and floods.

The development of a low-cost technology enables and allows its deployment and access, providing environmental sanitation and carbon credits, Figure 7 illustrates the system in place in communities. Figure 8 illustrates the system installed to burn the biogas surplus in systems where the energy is used.

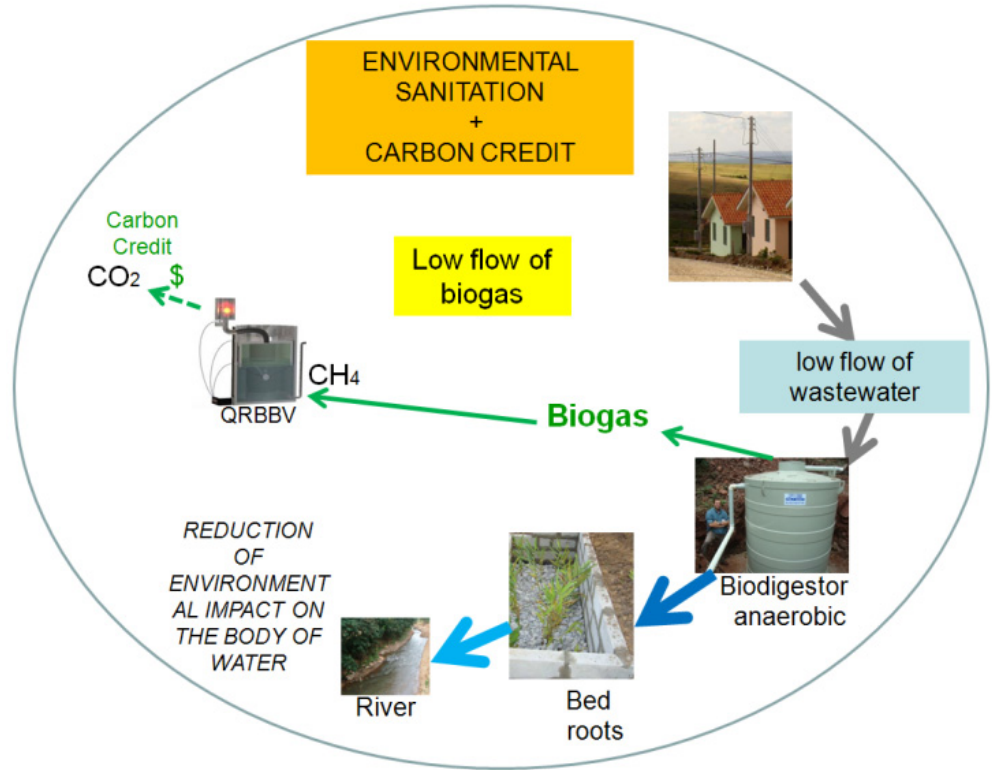

Figure 7: Relation of QRBBV with the environmental sanitation of biogas and sewage. 


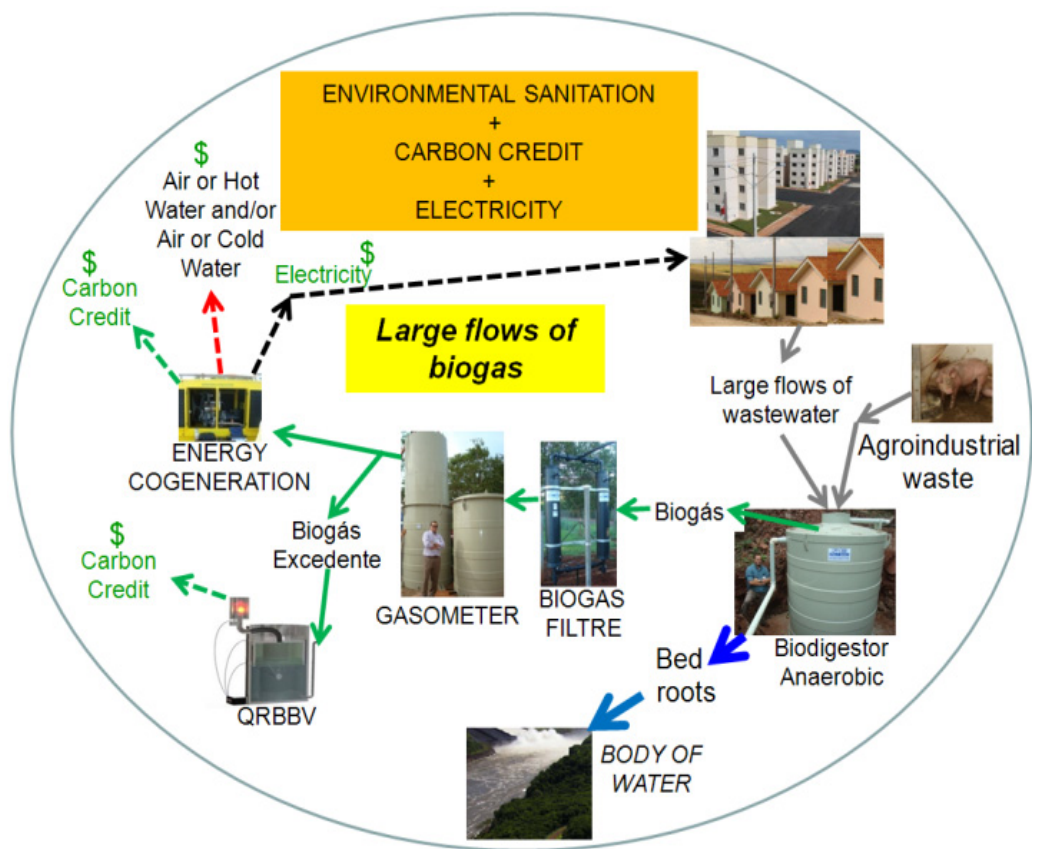

Figure 8: Example of situation where the large production of biogas enables their exploitation and use of energy by burning biogas QRBBV surplus.

\section{Conclusions}

It can be concluded that the proposed system is perfectly feasible from an environmental standpoint, since it avoids the undesirable emission of methane in the biogas in the atmosphere, converting it into carbon dioxide. In this equipment, the burning of biogas can be quantified, with guaranteed burning biogas process necessary to transform the methane into carbon dioxide, with significantly less potential to generate greenhouse gases.

Although the automatic burner system was designed based on low-cost electronic circuits, mechanical solutions with simple and easy installation, the economic viability of the system depends on the interaction with other systems. In case when a company responsible for sewage collection account the amount of methane converted to carbon dioxide and claim the carbon credits earned by systems installed, the economic viability will be ensured.

Already the economic viability of the system depends on the interaction of various systems in the case, when a concessionaire responsible for the collection of sewage calculates the amount of methane converted to carbon dioxide and claims the carbon deposits obtained by the systems installed. 


\section{References}

[1] Turns, SR, An Introduction to Combustion - Concepts and Applications, second edition, McGraw-Hill, International Editions, 2000.

[2] Shindengen, available here www.shindengen.com.jp, access on 10/02/2007.

[3] Littelfuse, www.littelfuse.com available on site, access on 15/02/2007.

[4] Nóbrega, S. J., Equipment Electronic Ignition Stove, and Process of Resin Composition for Encapsulation, Journal of Industrial Patents, RPI 1195, PI9204709, 1993.

[5] Invensysappliance, available at: www.invensysappliance.com.br access on 10/10/2008.

[6] Marcelino, M. A., Report of the specifications of Plants of light, FUNEP Contract/Brascabos 1040/06, September, 2006.

[7] Marcelino, M. A., Intelligent timer with Signaling for Preventive Maintenance, req. Patent Application with the INPI, PI000703940-9, Brazil, July, 2007. 